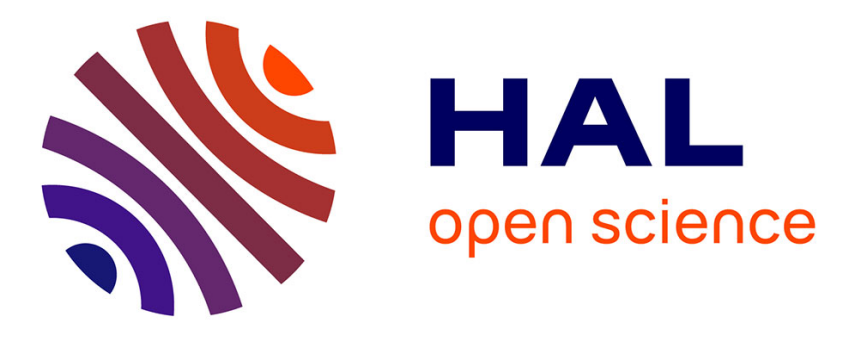

\title{
Psychopathological traits in college students from top-ranking french schools: Do autistic features impair success in science when associated with schizotypal traits?
}

Laura Choteau, Patrick Raynal, Nelly Goutaudier, Henri Chabrol

\section{To cite this version:}

Laura Choteau, Patrick Raynal, Nelly Goutaudier, Henri Chabrol. Psychopathological traits in college students from top-ranking french schools: Do autistic features impair success in science when associated with schizotypal traits?. Psychiatry Research, 2016, 237, pp.218-223. 10.1016/j.psychres.2016.01.038 . hal-03193794

\author{
HAL Id: hal-03193794 \\ https://hal.science/hal-03193794
}

Submitted on 9 Apr 2021

HAL is a multi-disciplinary open access archive for the deposit and dissemination of scientific research documents, whether they are published or not. The documents may come from teaching and research institutions in France or abroad, or from public or private research centers.
L'archive ouverte pluridisciplinaire HAL, est destinée au dépôt et à la diffusion de documents scientifiques de niveau recherche, publiés ou non, émanant des établissements d'enseignement et de recherche français ou étrangers, des laboratoires publics ou privés. 
Psychopathological Traits in College Students from Top-Ranking French Schools: Do Autistic Features Impair Success in Science when Associated with Schizotypal Traits?

\author{
Laura Choteau§, Patrick Raynal§*, Nelly Goutaudier, Henri Chabrol \\ Département de Psychopathologie Clinique, de Psychologie de la Santé et de \\ Neurosciences \\ Octogone - Centre d'Etudes et de Recherches en Psychopathologie \\ Université de Toulouse II - Jean Jaurès, Toulouse, France
}

* Corresponding author: Dr. Patrick Raynal, OCTOGONE-CERPP, Université de ToulouseJean Jaurès, 5 allées Antonio Machado, 31058 Toulouse cedex 9, France. Phone: +33 619 103 173. Fax: +33 561504 918. E-mail: patrick.raynal@inserm.fr.

$\S$ Authors equally contribute to this study 


\section{Abstract}

The link between personality and the interest of individuals for science has not been thoroughly explored. In this report, we studied psychopathological traits in students studying science in French top-ranking institutions. Three hundred and forty seven individuals answered questionnaires assessing autistic and schizotypal dimensions, as well as anxiety, depression symptomatology and attachment quality. A cluster analysis based on autistic and schizotypal traits led to the identification of 4 distinct profiles: a "low trait cluster", a "moderate autistic trait cluster", a "moderate schizotypal trait cluster" and a "high trait cluster" (HTC) composed of individuals with high scores on both autistic and schizotypal scales. Each cluster represented 20.1 to $27.1 \%$ of participants and was clearly different from the three others, both on autistic and on schizotypal dimensions. These groups could be also typified by their level of anxiety, depression or degraded attachment, which are proportional to the extent of psychopathological traits. Moreover, students from the HTC cluster displayed lower academic results, thus implying that autistic traits might impair success in science when they are associated with moderate schizotypal personality features. This study also suggests that depression and anxiety might mediate performance inhibition in the HTC group.

Keywords: Autistic personality traits, Schizotypal personality traits, Science students, Anxiety, Depression. 


\section{Introduction}

Personality is considered as a major determinant in individuals involved in scientific activities. Indeed personality is thought to influence individuals at the level of two related but distinct concepts: their interest in science, as well as their aptitudes (Feist, 2006). Nevertheless, the link between psychopathological traits and the involvement of individuals in scientific backgrounds has not been thoroughly examined. In the last decade, a major breakthrough in this field was brought to light by studies showing that personality traits associated with autism spectrum disorders strongly influence the scientific abilities of individuals (Baron-Cohen et al., 1998). This was initially based on the observation of higher frequency of autism cases in families of students involved in mathematics, physics or engineering, in comparison with families of individuals studying literature or humanities (Baron-Cohen et al., 1998; Baron-Cohen et al., 2007). Following these reports, it was subsequently shown that students involved in scientific programs display themselves marked features of autistic personality, compared with peers studying literature or social sciences (Baron-Cohen et al., 2001).

Other studies exploring the link between personality and scientific aptitudes suggested that features such as empathy or schizotypy are less frequent in scientific students than in individuals studying humanities. In contrast, students involved in science appeared to be characterized by a more pronounced "systematizing" dimension, which can be defined as an ability to handle any type of system (abstract, mechanical, organizable...) (Nettle, 2006; Wakabayashi et al., 2006; Rawlings and Locarnini, 2008).

To date the link between personality and scientific aptitudes appears to be an open question. For example, recent data suggested that the performance of students in mathematics, an abstract system, does not necessarily correlate with the systematizing 
dimension of individuals (Morsanyi et al., 2012). Furthermore, the notion that schizotypal traits are low in scientists is somewhat surprising, considering the numerous evidences showing that schizotypal features are highly correlated with the ability of individuals to be creative (Rawlings and Locarnini, 2008; Nelson and Rawlings, 2010; MacPherson and Kelly, 2011; Fink et al., 2013). And creativity can be hardly distinguished from aptitudes to achieve scientific discoveries, notably when serendipity (i.e., unexpected inventions) is involved (cf. the discovery of penicillin by Fleming or the medical use of X rays by Röntgen) (Rosenman, 1988; Stoskopf, 2005; Yewdell, 2008).

Other psychopathological dimensions could characterize students involved in science. Indeed, schizotypal or autistic dimensions can be associated with depression symptoms or anxiety in sample of non-clinical students (Lewandowski et al., 2006; Rey et al., 2009; Morvan et al., 2011), comorbidities also observed in individuals with autism spectrum disorders (Greenaway and Howlin, 2010; McPheeters et al., 2011; Pouw et al., 2013). Moreover, attachment security could be an interesting dimension to examine in students involved in science. Indeed, insecure attachment has been linked with autism (Rutgers et al., 2004; Haltigan et al., 2011), which led to a possible treatment of autism with oxytocin, an hormone regulating infant attachment and linking social signals with cognition (Canitano, 2014). Insecure attachment has been also involved in schizotypy (Berry et al., 2008; Meins et al., 2008). Besides examining peer attachment, parental attachment may be of interest in college students. Indeed, a meta-analytic review found a small-to-medium relationship between indicators of parental attachment quality and favorable adjustment outcomes $(r=.23)$ in this population (Mattanah et al., 2011). More specifically, a study found that parental attachment contributed to romantic attachment among college students with autistic traits. (Lamport and Turner, 2014). Moreover, 
besides depression and insecure attachment, schizotypal traits are frequently associated with the use of psychoactive substances including alcohol or cannabis (Nunn et al., 2001; Esterberg et al., 2009; Fridberg et al., 2011) .

Taken as a whole, the available literature on the subject thus suggests that empirical data on personality traits in students studying science are rather scarce and poorly consistent. Therefore, this current study aims at identifying a typology of scientific students on the basis of psychopathological traits, using a cluster analysis approach rather than a factorial/correlational approach. Indeed the variable-centered approach may underestimate the heterogeneity of individuals and proposes general findings and theoretical elaborations that might be somewhat artificial and inaccurate, as they result from the examination of samples combining dissimilar and disparate groups of individuals. Unlike this approach, the person-centered one, unraveling homogeneous groups of individuals, may reveal group-specific relations between variables that are obscured or masked by a globalizing variable-centered approach. It is important to note that cluster analyses are useful for determining the presence of subgroups of individuals with specific profiles of personality traits. In addition, these analyses are valuable for assessing whether these subgroups are varying in frequencies of behaviors and/or symptoms. We thus expected to obtain clusters differing on autistic and schizotypal traits and we next examined whether these clusters could be differentiated on other variables, including attachment, anxiety and depression and academic results. 


\section{Methods}

\subsection{Participants}

Participants were recruited through seven most famous French scientific schools, selected according to the international classification of Shanghai (2012). The schools used in this study are highly specialized in sciences and do not provide teachings in non-science matters (except English or other foreign langages as minor courses). Therefore, students from these schools are almost exclusively involved in studying scientific matters, with $90 \%$ of their classes and exams related to these disciplines. Informed consent was obtained from all participants and no compensation was offered. The procedures were approved by the ethics committee of the research ward. The sample was composed of 347 students (Mean age=21.8; S.D.=2, 44.1\% female, 55.9\% male; Table 1). Regarding their personal situation, $45 \%$ of participants lived by themselves, $22.8 \%$ were living with a partner, $17.6 \%$ with a roommate and $14.7 \%$ with their parents. About the discipline studied, $50 \%$ of students had a major in Biology, $26.2 \%$ in Computer Sciences and the rest studied Mathematics, Physics or Engineering (Table 1). A large majority (70.9\%) of participants were B.A. students, the rest being involved at the M.A. level. About academic performances, only $6.3 \%$ of participants failed during the last semester. For others, the distinction "cum laude" was the most frequent $(32.6 \%)$.

\subsection{Measures}

\subsubsection{Autistic traits}

Autistic traits were measured using the Autism spectrum Quotient (AQ) (BaronCohen et al., 2001). This questionnaire includes 50 items (e.g., "I find social situations easy"). For each statement, participants indicated their extent of endorsement on a 4- 
point Likert scale ranging from "definitely agree" to "definitely disagree". "Definitely disagree" or "slightly disagree" responses were scored 1 point, except for the following items inversely scored : 2, 4, 5, 6, 7, 9, 12, 13, 16, 18, 19, 20, 21, 22, 23, 26, 33, 35, 39, 41, $42,43,45$, and 46. A score above 25 is considered as a cutoff for distinguishing individuals with significant level of autistic traits, whilst a score above 32 characterizes individuals with autism spectrum disorder. Cronbach' $\alpha$ coefficient ranged from 0.63 to 0.77 in the report by Baron-Cohen et al. and it was 0.68 in this current study.

\subsubsection{Schizotypal traits}

Schizotypal traits were evaluated using the Schizotypal Personality Questionnaire (SPQ) (Raine, 1991; Raine and Benishay, 1995) under its French adaptation (Dumas et al., 1999). This self-report questionnaire is constituted of 74 items under the Yes/No format (e.g., "People sometimes find me aloof and distant"). Each item is scored $0 / 1$ (No/Yes) and thus the total score ranges from 0 to 74 , a high score indicating the presence of schizotypal traits. The cut-offs for the top and bottom ten percents of SPQ scores are respectively 41/74 and 12/74 (Raine, 1991). The internal consistency (Cronbach's $\alpha$ coefficient) was 0.90 both in Raine's report and in the current study.

\subsubsection{Parental and peer attachment}

Parental and peer attachment was measured using a short version of the Inventory of Parent and Peer Attachment (IPPA) (Armsden and Greenberg, 1987). This questionnaire is composed of 2 subscales measuring attachment to parents or to peers (12 items each) (e.g., "My parents respect my feelings"). Participants indicate how often each statement is true for them on a 5-point Likert scale ("Almost never or never true/Seldom true/Sometimes true/Often true/Almost always or always true"). Each 
response was scored from 5 to 1, respectively, except in the case of items negatively worded which were inversely scored. A total score ranging from 12 to 60 can be calculated for each subscale, with a high score suggesting an insecure attachment style. The Cronbach's $\alpha$ coefficient ranged from 0.72 to 0.90 in the report by Armsden and Greenberg. In this current study, this coefficient was 0.63 (parent subscale) and 0.55 (peer subscale).

\subsubsection{Anxiety and depressive symptomatology}

Anxiety and depressive symptomatology were evaluated using the Hospital Anxiety Depression Scale (HADS) (Zigmond and Snaith, 1983). This questionnaire is composed of two 7-items subscales measuring depressive or anxiety symptoms. The respondent is asked to indicate how frequently she/he experienced a particular symptom (e.g., "I feel tense or wound up"). Responses are made on a 4-point Likert scale, ranging from 0 , indicating that a symptom was present "rarely or none of the time" to 3 , indicating that a symptom was present "most or all the time". For each subscale, the total score ranges from 0 to 21 and a score above 10 suggests the presence of a depressive or an anxiety disorder. In the current study, the internal consistency was 0.74 (anxiety) and 0.66 (depression).

\subsubsection{Substance use}

The Alcohol Use Disorders Identification Test (AUDIT) was used to evaluate alcohol use (Saunders et al., 1993). This scale contains 10 items (e.g., "How often do you drink beverages containing alcohol?"). Participants are invited to respond on a 5-points Likert scale $(0=$ "Never", $1=$ "Once a month or less", $2=$ "Two to four times a month", 3= "Two to three times a week", 4= "At least four times a week"). Individuals scoring higher than 8 are considered with a potentially hazardous alcohol consumption. 
Cannabis use was measured with the Cannabis Use Disorder Identification Test-Revised (CUDIT-R) (Adamson et al., 2010). It is composed of 8 questions (e.g., "How often, during the last six months, have you had a problem with your memory or concentration after using cannabis?") and participants respond on a 5-points Likert scale similar to the AUDIT (cf. above).

\subsubsection{Personal information}

This study collected general information regarding the participants (age, sex, year of study, discipline and academic results during the past semester). The variable "academic results" was obtained by asking students their overall grade for the last semester (Failed; Passed with grade $\geq 10 / 20$ and $<12 / 20$; Passed with grade $\geq 12 / 20$ and $<14 / 20$; Passed with grade $\geq 14 / 20$ and $<16 / 20$; Passed with grade $\geq 16 / 20$ ). Scoring of the "discipline" variable was achieved as follows: 1: Mathematics; 2: Physics and Chemistry; 3: Computer sciences; 4: Engineering; 5: Agronomics and Biology.

\subsection{Statistical analysis}

A cluster analysis was performed to identify distinct profiles of participants based on their scores in autistic and schizotypal dimensions. This was achieved by standardizing as z-scores the participants scores for each dimension. A hierarchical cluster analysis was then conducted (Ward's method with squared Euclidean distance). The dendrogram and the agglomeration schedule were used to identify the number of clusters. Then, K-means clustering was used to assign each individual to the identified clusters. Statistical analyses were performed using Statistica 10. 


\section{Results}

\subsection{Descriptive statistics}

The mean score of participants regarding the autistic dimension was 17.8 $(\mathrm{SD}=5.6) .13 .5 \%$ of participants obtained a score above 25 , whilst 4 individuals $(1.1 \%)$ obtained a score suggesting an autism spectrum disorder. Regarding schizotypal personality traits, the mean score of participants was $20.4(\mathrm{SD}=11)$. The mean scores of participants with respect to the depressive and anxiety dimensions were 4.1 and 7.2 $(\mathrm{SD}=2.7$ and 3.4), respectively.

Regarding male/female comparison (Table 2), t-test analysis showed significant differences $(\mathrm{p}<0.05)$ only in terms of anxiety and substance uses (alcohol or cannabis).

\subsection{Cluster analysis}

Based both on the dendrogram and on the aggregation curve, a four-cluster solution was identified. A discriminant analysis showed clear differences between the four clusters (Wilks' $\lambda=0.10, \mathrm{p}<0.001$ ) with $98.6 \%$ of original cases correctly classified. The first cluster ( $\mathrm{n}=95,27.4 \%$ of participants), named "Low Trait Cluster" (LTC), is composed with individuals displaying the lowest scores on both autistic and schizotypal dimensions (Figure 1). The second group (n=88, 25.4\%) was called "Moderate Autistic Trait Cluster" (MATC) as it is characterized by students with a high score on the autistic dimension and a low schizotypy score. The $3^{\text {rd }}$ cluster $(n=94,27.1 \%)$ includes participants with higher schizotypal features than autistic traits and was therefore named "Moderate Schizotypal Trait Cluster" (MSTC). The $4^{\text {th }}$ group (n=70, 20.1\%) was called "High Trait Cluster" (HTC) as it is composed of individuals with high scores in terms of both autistic and schizotypal scales. 
We then compared these clusters on different dimensions using ANOVA and posthoc test. At the level of autistic or schizotypal traits, cluster comparison showed significant variations between groups, as the four clusters are all different from each others when considering either autistic or schizotypal traits (Table 3). We next compared these clusters on other dimensions, including anxiety and depression symptoms, attachment quality, substance use and academic performances.

Firstly, these clusters appeared to be similar to each others in terms of gender, discipline studied or academic level of the participants, thereby ruling out a major influence of these variables on the different clusters (Table 3). In terms of anxiety and depression, cluster comparison showed that students with autistic (MATC) or schizotypal (MSTC) traits, or both (HTC), display stronger scores than individuals with low traits (LTC), the highest scores being observed in the group including students with most prominent traits (HTC).

These clusters could be also differentiated from each others with respect to attachment quality. Indeed, when considering either parental or peer attachment, the HTC group shows a less secure attachment (higher score) than other clusters. It is also noteworthy that participants from MATC or MSTC display a more insecure attachment to peer, compared to LTC individuals. Regarding substance use, individuals wih the most marked traits (HTC) seemed less prone to drink alcohol compared to the three other groups.

Finally, in terms of academic performance, HTC individuals obtained lower results than their peers from LTC or MSTC. Taken together, these data indicate that four groups can be identified when classifying science students according to autistic and schizotypal personality traits. These groups are also characterized by their level of 
anxiety and depression symptoms which are proportional to the extent of psychopathological traits.

\section{Discussion}

This study aimed at a better understanding of the personality of students from top-ranking scientific schools. Based on the evaluation of autistic and schizotypal personality traits and on cluster analysis, we identified four distinct groups of participants. These clusters were similar in size but displayed significant differences in terms of psychopathological features, as each of these groups was clearly distinct from the three other clusters, both on autistic and schizotypal dimensions.

Regarding the validity of our study, it is worthwhile mentioning that the sample analysed in this study appears to be similar to other non clinical populations of students described in the literature. For instance, the mean AQ score obtained in this study (17.8, $S D=5.6)$ is nearly identical to that of English science students $(M=17.6, S D=6.4)$ (BaronCohen et al., 2001). Similarly, the mean SPQ score obtained by participants in this current work $(20.4, \mathrm{SD}=11)$ is comparable to the value of $23.6(\mathrm{SD}=12.1)$ reported in a sample of non-clinical French students (Dumas et al., 1999). On the same theme, regarding depression and anxiety scores, our sample $(\mathrm{M}=4.09, \mathrm{SD}=2.7 ; \mathrm{M}=7.2, \mathrm{SD}=3.3)$ is also similar to those of English students $(M=4.3, S D=3 ; M=8.8, S D=3.9)$, respectively (Andrews and Wilding, 2004).

We then took advantage of these well-defined clusters to explore other psychopathological characteristics which may be associated with autistic or schizotypal personality traits. We thus observed that these traits are frequently associated with anxiety, depression symptoms, and insecure attachment. Indeed, compared to 
individuals with a low level of traits (LTC), participants with autistic or schizotypal features displayed higher signs of anxiety and depression. Furthermore, HTC individuals, displaying marked traits on both autistic and schizotypal dimensions, showed an even stronger level of anxiety and depression.

Consequently, these results provide support to the notion that depression and anxiety are inherent to autistic or schizotypal personality traits (Braunstein-Bercovitz, 2000; Cohen and Matthews, 2010; Fonseca-Pedrero et al., 2011), even though an open question remains the contribution of affective or anxiety disorders to the overlap between autistic and schizotypal personality traits (Mealey et al., 2014).

Our study also took into account the quality of attachment. We thus observed that, compared to individuals with low traits, peer attachment is degraded in students with autistic or schizotypal traits, and even worse in those with both features. Therefore these observations are in line with previous reports describing attachment issues in individuals with autistic personality traits (Rutgers et al., 2004; Haltigan et al., 2011; Canitano, 2014).

Our study also shows that, in contrast to peer attachment, parental attachment is preserved in individuals with only autistic traits (MATC) or in those with only schizotypal propensity (MSTC), even though parental attachment is significantly degraded in students with both autistic and schizotypal traits (HTC). Therefore this suggests that attachment, considering either parental or peer bonds, relies on distinct factors, differentially altered in the case of individuals with autistic or schizotypal traits. Recently, a polymorphism of the gene encoding the oxytocin receptor has been proposed to link autism and defective attachment (Chen and Johnson, 2012). Therefore, 
one may wonder whether this polymorphism could illustrate the fact that autistic and schizotypal traits differentially influence the attachment to parent and to peer.

The observation that a significant proportion $(\approx 20 \%)$ of students display both autistic and schizotypal traits (HTC group) raises the question of overlap between these personality features. At various times, autism and schizophrenia have been regarded as closely related, or, alternatively, as non-overlapping and incompatible (King and Lord, 2011). For instance, a "diametric model" tentatively placed autism and schizotypy on opposite ends of an axis of social cognition (Crespi and Badcock, 2008). Nevertheless, recent studies suggested the existence of elements shared by these two conditions. These include functional aspects, notably common deficits in mirror neurons and a partial genetic overlap between the two conditions (King and Lord, 2011). In addition, autism and schizotypy were found to display positive correlations between each other in the domains of social skills and communication (Hurst et al., 2007; Russell-Smith et al., 2011). A recent study further supported this view by showing a strong and positive association of autistic-like communication with interpersonal schizotypy in a nonclinical population of students (Dinsdale et al., 2013).

An interesting insight on scientific student personality brought by this study is that scientific skills cannot be reduced to autistic traits (Baron-Cohen et al., 2001). In fact, the personality features involved in success in the field of science appear to be more complex. Indeed, our data show that "HTC" individuals obtained significantly poorer academic results than individuals with low traits. Remarkably, HTC individuals cannot be considered as a minor group of science students, as they represent $20 \%$ of the population (Table 3). Consequently, these data suggest that, in a significant fraction of students, autism-spectrum traits appeared as a factor impairing success in the field of 
science, at least when these traits are associated with moderate schizotypal personality elements.

The reason(s) for this intriguing observation is (are) not known. However, individuals from the HTC group display higher levels of anxiety and depression than other clusters, symptoms which may have an unfavourable outcome on academic results. As a first approach to test this hypothesis, we performed a covariance analysis of academic performance while controlling for anxiety or depression. The results showed that the HTC group was not significantly different from other clusters (data not shown), which strengthened the idea that higher anxiety and depression scores in the HTC group might account for their lower academic performance relative to the other three groups. Nevertheless additional studies are required to further explore whether these symptoms contribute significantly to the relative lack of academic performance in the HTC group.

Given that no control group was used to compare the effect of autistic and schizotypal traits on academic performances, our results have to be taken carefully. Moreover, in order to provide an in-depth examination of the role of autistic and schizotypal traits on academic performances, conducting comparison studies is warranted. Indeed, replicating the current study on various samples, including students involved in non-scientific courses, might also be useful to test the stability of our findings across populations.

Nevertheless, in light of our study professionals working with college students from top-ranking French school should pay attention to personality traits as they might be risk-factors for mental health issues. While a systematic screening would not be worth considering and might be perceived as stigmatizing, paying attention to warning 
signs of potential personality traits is warranted. As an example, individuals presenting autistic traits might be characterized by socializing issues (e.g., preferring to be alone or being overly-friendly) which could be easily perceivable. Raising teachers and academic staff awareness about personality characteristics and warning signs appears of prime importance for preventing mental health issues and associated impairments.

Contributors: LC collected and analyzed the data; PR wrote the manuscript and performed statistical analysis; HC and NG designed the study and discussed the results. The authors do not have conflict of interest. 
References

Adamson, S.J., Kay-Lambkin, F.J., Baker, A.L., Lewin, T.J., Thornton, L., Kelly, B.J., Sellman, J.D., 2010. An improved brief measure of cannabis misuse: The Cannabis Use Disorders Identification Test-Revised (CUDIT-R). Drug and Alcohol Dependence 110, 137-143.

Andrews, B., Wilding, J.M., 2004. The relation of depression and anxiety to life-stress and achievement in students. British Journal of Psychology 95, 509-521.

Armsden, G.C., Greenberg, M.T., 1987. The Inventory of Parent and Peer Attachment Individual-Differences and Their Relationship to Psychological Well-Being in Adolescence. Journal of Youth and Adolescence 16, 427-454.

Baron-Cohen, S., Bolton, P., Wheelwright, S., Scahill, V., Short, L., Mead, G., Smith, A., 1998. Autism occurs more often in families of physicists, engineers, and mathematicians. Autism 2, 296-301.

Baron-Cohen, S., Wheelwright, S., Burtenshaw, A., Hobson, E., 2007. Mathematical talent is linked to autism. Human Nature 18, 125-131.

Baron-Cohen, S., Wheelwright, S., Skinner, R., Martin, J., Clubley, E., 2001. The autismspectrum quotient (AQ): Evidence from Asperger Syndrome/high-functioning autism, males and females, scientists and mathematicians. Journal of Autism and Developmental Disorders 31, 603-603.

Berry, K., Barrowclough, C., Wearden, A., 2008. Attachment theory: A framework for understanding symptoms and interpersonal relationships in psychosis. Behaviour Research and Therapy 46, 1275-1282.

Braunstein-Bercovitz, H., 2000. Is the attentional dysfunction in schizotypy related to anxiety? Schizophrenia Research 46, 255-267.

Canitano, R., 2014. New experimental treatments for core social domain in autism spectrum disorders. Frontiers in Paediatrics doi: 10.3389/fped.2014.00061

Chen, F.S., Johnson, S.C., 2012. An Oxytocin Receptor Gene Variant Predicts Attachment Anxiety in Females and Autism-Spectrum Traits in Males. Social Psychological and Personality Science 3, 93-99.

Cohen, A.S., Matthews, R.A., 2010. Primary and and secondary negative schizotypal traits in a large non-clinical sample. Personality and Individual Differences 49, 419-424.

Crespi, B., Badcock, C., 2008. Psychosis and autism as diametrical disorders of the social brain. Behavioral and Brain Sciences 31, 241-261.

Dinsdale, N.L., Hurd, P.L., Wakabayashi, A., Elliot, M., Crespi, B.J., 2013. How Are Autism and Schizotypy Related? Evidence from a Non-Clinical Population. Plos One 8, e63316.

Dumas, P., Rosenfeld, F., Saoud, M., Dalery, J., d'Amato, T., 1999. Schizotypal Personality Questionnaire (SPQ). Presentation of the French translation and preliminary results in a sample of French students. Encephale-Revue De Psychiatrie Clinique Biologique Et Therapeutique 25, 315-322.

Esterberg, M.L., Goulding, S.M., McClure-Tone, E.B., Compton, M.T., 2009. Schizotypy and nicotine, alcohol, and cannabis use in a non-psychiatric sample. Addictive Behaviors 34, 374-379. 
Feist, G.J., 2006. How development and personality influence scientific thought, interest, and achievement. Review of General Psychology 10, 163-182.

Fink, A., Weber, B., Koschutnig, K., Benedek, M., Reishofer, G., Ebner, F., Papousek, I., Weiss, E.M., 2013. Creativity and schizotypy from the neuroscience perspective. Cognitive, Affective, \& Behavioral Neuroscience 14, 378-387.

Fonseca-Pedrero, E., Paino, M., Lemos-Giraldez, S., Muniz, J., 2011. Schizotypal traits and depressive symptoms in nonclinical adolescents. Comprehensive Psychiatry 52, 293300.

Fridberg, D.J., Vollmer, J.M., O'Donnell, B.F., Skosnik, P.D., 2011. Cannabis users differ from non-users on measures of personality and schizotypy. Psychiatry Research 186, 46-52.

Greenaway, R., Howlin, P., 2010. Dysfunctional Attitudes and Perfectionism and Their Relationship to Anxious and Depressive Symptoms in Boys with Autism Spectrum Disorders. Journal of Autism and Developmental Disorders 40, 1179-1187.

Haltigan, J.D., Ekas, N.V., Seifer, R., Messinger, D.S., 2011. Brief Report: Attachment Security in Infants At-Risk for Autism Spectrum Disorders. Journal of Autism and Developmental Disorders 41, 962-967.

Hurst, R.M., Nelson-Gray, R.O., Mitchell, J.T., Kwapil, T.R., 2007. The relationship of Asperger's characteristics and schizotypal personality traits in a non-clinical adult sample. Journal of Autism and Development Disorders 37, 1711-1720.

King, B.H., Lord, C., 2011. Is schizophrenia on the autism spectrum? Brain Research 1380, 34-41.

Lamport, D., Turner, L.A., 2014. Romantic Attachment, Empathy, and the Broader Autism Phenotype among College Students. Journal of Genetic Psychology 175, 202-213.

Lewandowski, K.E., Barrantes-Vidal, N., Nelson-Gray, R.O., Clancy, C., Kepley, H.O., Kwapil, T.R., 2006. Anxiety and depression symptoms in psychometrically identified schizotypy. Schizophrenia Research 83, 225-235.

MacPherson, J.S., Kelly, S.W., 2011. Creativity and positive schizotypy influence the conflict between science and religion. Personality and Individual Differences 50, 446450 .

Mattanah, J.F., Lopez, F.G., Govern, J.M., 2011. The Contributions of Parental Attachment Bonds to College Student Development and Adjustment: A Meta-Analytic Review. Journal of Counseling Psychology 58, 565-596.

McPheeters, M.L., Davis, A., Navarre, J.R., Scott, T.A., 2011. Family Report of ASD Concomitant with Depression or Anxiety Among US Children. Journal of Autism and Developmental Disorders 41, 646-653.

Mealey, A., Abbott, G., Byrne, L.K., McGillivray, J., 2014. Overlap between autistic and schizotypal personality traits is not accounted for by anxiety and depression. Psychiatry Research 219, 380-385.

Meins, E., Jones, S.R., Fernyhough, C., Hurndall, S., Koronis, P., 2008. Attachment dimensions and schizotypy in a non-clinical sample. Personality and Individual Differences 44, 1000-1011. 
Morsanyi, K., Primi, C., Handley, S.J., Chiesi, F., Galli, S., 2012. Are systemizing and autistic traits related to talent and interest in mathematics and engineering? Testing some of the central claims of the empathizing-systemizing theory. British Journal of Psychology 103, 472-496.

Morvan, Y., Tibaoui, F., Bourdel, M.C., Loo, H., Akiskal, K.K., Akiskal, H.S., Krebs, M.O., 2011. Confirmation of the factorial structure of temperamental autoquestionnaire TEMPS-A in non-clinical young adults and relation to current state of anxiety, depression and to schizotypal traits. Journal of Affective Disorders 131, 37-44.

Nelson, B., Rawlings, D., 2010. Relating Schizotypy and Personality to the Phenomenology of Creativity. Schizophrenia Bulletin 36, 388-399.

Nettle, D., 2006. Schizotypy and mental health amongst poets, visual artists, and mathematicians. Journal of Research in Personality 40, 876-890.

Nunn, J.A., Rizza, F., Peters, E.R., 2001. The incidence of schizotypy among cannabis and alcohol users. Journal of Nervous and Mental Disease 189, 741-748.

Pouw, L.B.C., Rieffe, C., Stockmann, L., Gadow, K.D., 2013. The link between emotion regulation, social functioning, and depression in boys with ASD. Research in Autism Spectrum Disorders 7, 549-556.

Raine, A., 1991. The SPQ - a Scale for the Assessment of Schizotypal Personality Based on DSM-III-R Criteria. Schizophrenia Bulletin 17, 555-564.

Raine, A., Benishay, D., 1995. The SBQ-B: A brief screening instrument for schizotypal personality disorder. Journal of Personality Disorders 9, 346-355.

Rawlings, D., Locarnini, A., 2008. Dimensional schizotypy, autism, and unusual word associations in artists and scientists. Journal of Research in Personality 42, 465-471.

Rey, G., Jouvent, R., Dubal, S., 2009. Schizotypy, Depression, and Anxiety in Physical and Social Anhedonia. Journal of Clinical Psychology 65, 695-708.

Rosenman, M.F., 1988. Serendipity and Scientific Discovery. Journal of Creative Behavior 22, 132-138.

Russell-Smith, S.N., Maybery, M.T., Bayliss, D.M., 2011. Relationships between autisticlike and schizotypy traits: An analysis using the Autism Spectrum Quotient and OxfordLiverpool Inventory of Feelings and Experiences. Personality and Individual Differences 51, 128-132.

Rutgers, A.H., Bakermans-Kranenburg, M.J., van Ijzendoorn, M.H., van Berckelaer-Onnes, I.A., 2004. Autism and attachment: a meta-analytic review. Journal of Child Psychology and Psychiatry 45, 1123-1134.

Saunders, J.B., Aasland, O.G., Babor, T.F., Delafuente, J.R., Grant, M., 1993. Development of the Alcohol-Use Disorders Identification Test (Audit) - Who Collaborative Project on Early Detection of Persons with Harmful Alcohol-Consumption. Addiction 88, 791-804.

Stoskopf, M.K., 2005. Observation and cogitation: How serendipity provides the building blocks of scientific discovery. ILAR Journal 43, 332-337.

Wakabayashi, A., Baron-Cohen, S., Wheelwright, S., Goldenfeld, N., Delaney, J., Fine, D., Smith, R., Weil, L., 2006. Development of short forms of the Empathy Quotient (EQShort) and the Systemizing Quotient (SQ-Short). Personality and Individual Differences $41,929-940$. 
Yewdell, J.W., 2008. How to succeed in science: a concise guide for young biomedical scientists. Part I: taking the plunge. Nature Reviews in Molecular and Cellular Biology 9, 413-416.

Zigmond, A.S., Snaith, R.P., 1983. The Hospital Anxiety and Depression Scale. Acta Psychiatrica Scandinavica 67, 361-370. 


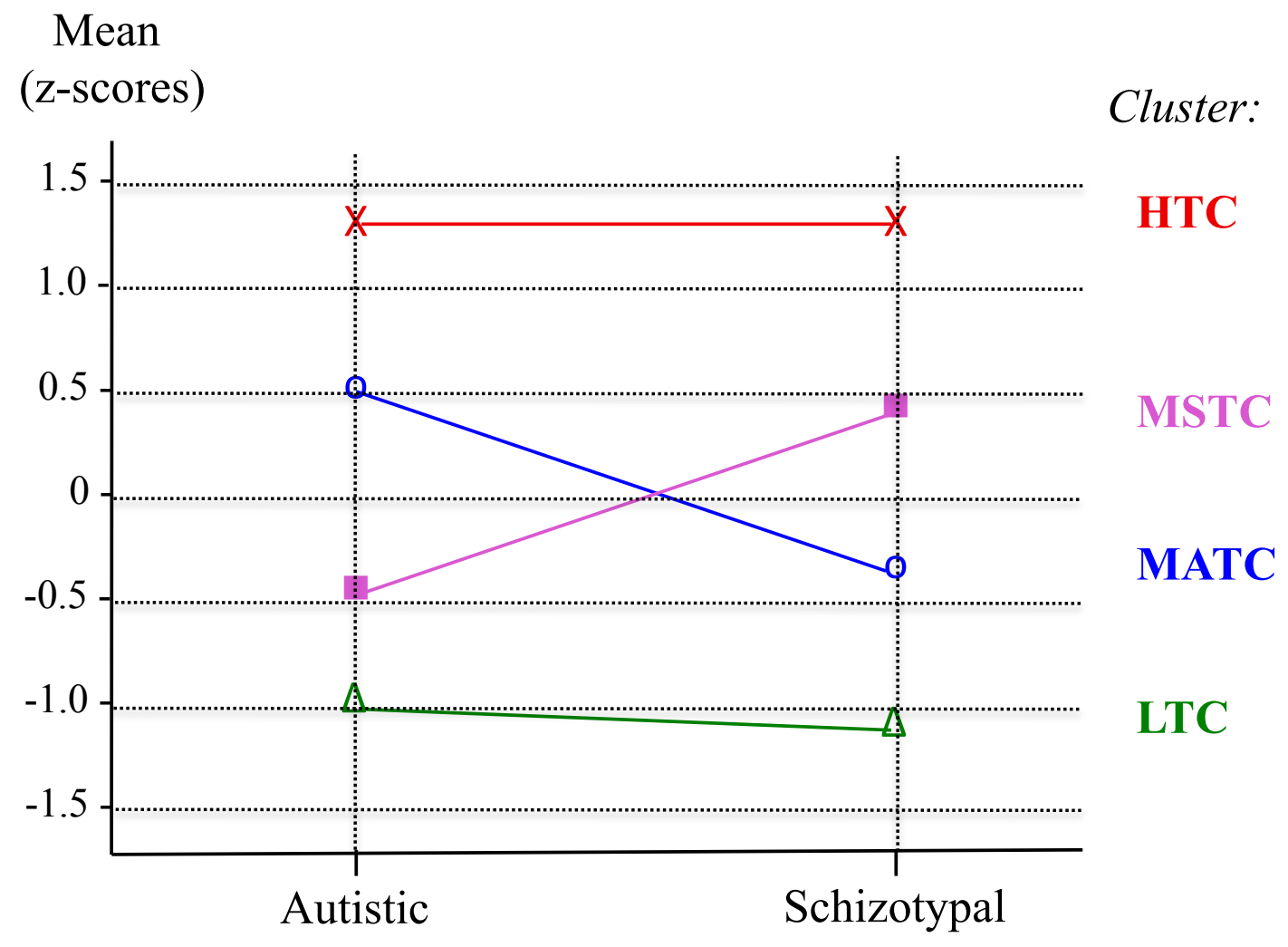

Dimensions

Figure 1. Four-cluster solution (LTC, MATC, MSTC and HTC) based on scores for the dimensions indicated on the $\mathrm{x}$-axis.

LTC: Low Trait Cluster

MATC: Moderate Autistic Traits Cluster

MSTC: Moderate Schizotypal Traits Cluster

HTC: High Trait Cluster 
Table 1

Sample characteristics $(N=347)$

\begin{tabular}{|c|c|c|c|}
\hline Variable: & & $\mathrm{n}$ & $\%$ \\
\hline \multirow[t]{2}{*}{ Gender } & - Female & 153 & 44.1 \\
\hline & - Male & 194 & 55.9 \\
\hline Age & $\mathrm{M}=21.84 \quad$ S.D. $=2.04$ & & \\
\hline \multirow[t]{4}{*}{ Personal situation } & - Single & 156 & 45.0 \\
\hline & - In a civil partnership & 79 & 22.8 \\
\hline & - Living with a roommate & 61 & 17.6 \\
\hline & - Living with parents & 51 & 14.7 \\
\hline \multirow[t]{5}{*}{ Discipline } & - Mathematics & 27 & 7.8 \\
\hline & - Computer Sciences & 92 & 26.2 \\
\hline & - Biology & 173 & 49.9 \\
\hline & - Engineering & 20 & 5.8 \\
\hline & - Physics & 35 & 10.1 \\
\hline \multirow[t]{3}{*}{ Academic level } & - B.A. & 171 & 49.3 \\
\hline & - B.A., final year & 74 & 21.3 \\
\hline & - M.A. & 102 & 29.4 \\
\hline \multirow[t]{5}{*}{ Academic performance } & - Failed & 22 & 6.3 \\
\hline & - Passed & 74 & 21.3 \\
\hline & - Cum laude & 113 & 32.6 \\
\hline & - Magna cum laude & 75 & 21.6 \\
\hline & - Summa cum laude & 63 & 18.2 \\
\hline
\end{tabular}


Table 2

Descriptive statistics of the sample $(N=347)$

\begin{tabular}{lcccc}
\hline & $\begin{array}{c}\text { Minimum } \\
\text { score }\end{array}$ & $\begin{array}{c}\text { Maximum } \\
\text { score }\end{array}$ & Mean & S.D. \\
\hline Autistic traits & 5 & 39 & 17.83 & 5.58 \\
Schizotypal traits & 1 & 53 & 20.41 & 11.04 \\
Depression & 0 & 13 & 4.09 & 2.74 \\
Anxiety & 0 & 17 & 7.19 & 3.37 \\
Parent attachment & 15 & 47 & 25.98 & 6.50 \\
Pair attachment & 12 & 56 & 27.57 & 8.11 \\
Alcohol & 0 & 7 & 2.44 & 1.57 \\
Cannabis & 0 & 8 & 0.53 & 1.39 \\
\hline
\end{tabular}


Table 3

Typology of 347 scientific students based on autistic and schizotypal traits: Cluster comparison using ANOVA and post-hoc test.

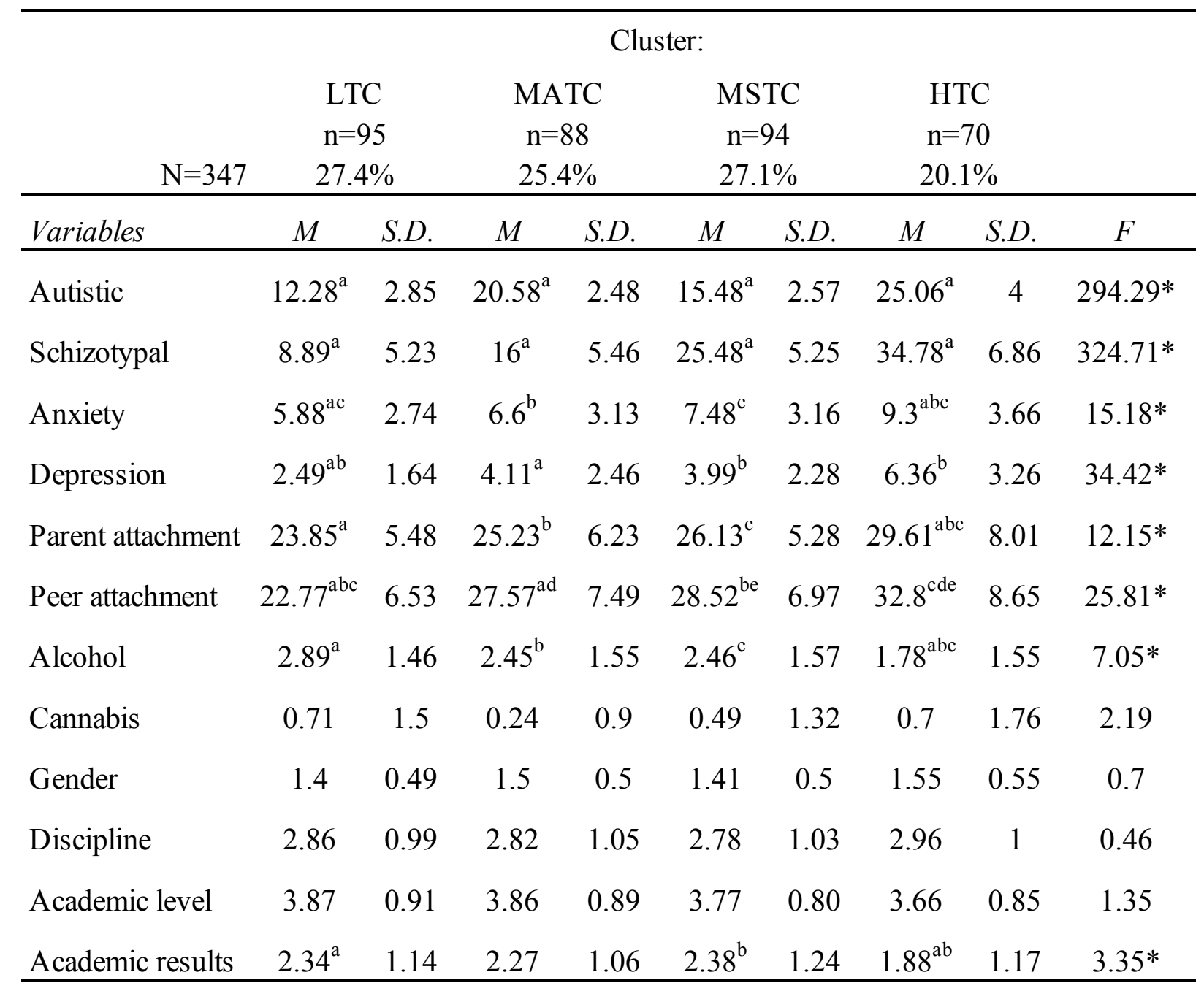

Note: Means with the same superscript letter are significantly different from each other (Tukey post-hoc test)

$* p<0.05$ 